\title{
Overseas Postgraduates' Experience of Learning: A Phenomenographic Study
}

\author{
Xiantong Zhao (Corresponding author) \\ Department of Lifelong and Comparative Education, UCL Institute of Education \\ London, United Kingdom \\ E-mail: zhaoxiantong1981@gmail.com
}

Received: April 11, 2015 Accepted: April 21, 2015 Published: April 24, 2015

doi:10.5296/jet.v2i2.7488 URL: http://dx.doi.org/10.5296/jet.v2i2.7488

\begin{abstract}
Although the subject - conceptions of learning - has been a significant research area in the phenomenographic tradition, little could be found for overseas students, especially Chinese postgraduates. The present research is a small scale study, which recruited five postgraduates, including three students pursuing their masters' degree and two doctoral students. The findings show that there are, in general, four conceptions of learning; encompassing learning as knowledge accumulation, applying, obtaining new perspectives, and a communicational process. Representing the internal relationship between different conceptions, the outcome space has finally been established based on these, which was then analysed within a two-dimensional framework. The results show that all of the postgraduates have good experience of learning.
\end{abstract}

Key words: Postgraduates; Conceptions of learning; Phenomenography

\section{Introduction}

Every year tens of thousands of Chinese students come to study in the UK, yet their experience of learning has seldom been investigated. Even though phenomenography has been developed for over 40 years, there are still some areas where it has seldom touched: for example, few studies have explored the conceptions of learning of overseas students and none have done so for the Chinese overseas postgraduates. Thus, it is the aim of this research study to uncover a group of masters' and doctoral students' qualitatively different ways of experiencing learning by using a phenomenographic approach.

\section{Phenomenography}

Marton (1994) defines phenomenography as: "the empirical study of the limited number of qualitatively different ways in which various phenomena in, and aspects of, the world around us are experienced, conceptualized, understood, perceived and apprehended" (p.4424). It is essentially "a way of - an approach to - identifying, formulating, tackling certain sorts of 


\section{Macrothink}

research questions, a specialisation that is particularly aimed at questions of relevance to learning and understanding in an educational setting" (Marton \& Booth, 1997, p. 111). It focuses on "the variations in ways people experience phenomena in their world", in other words, "the totality of ways in which people experience, or are capable of experiencing, the object of interest and interpret it in terms of distinctly different categories that capture the essence of the variation" (ibid. p. 121). Its critical characteristics can be insightfully illustrated by Triwell's (2006) figure below:

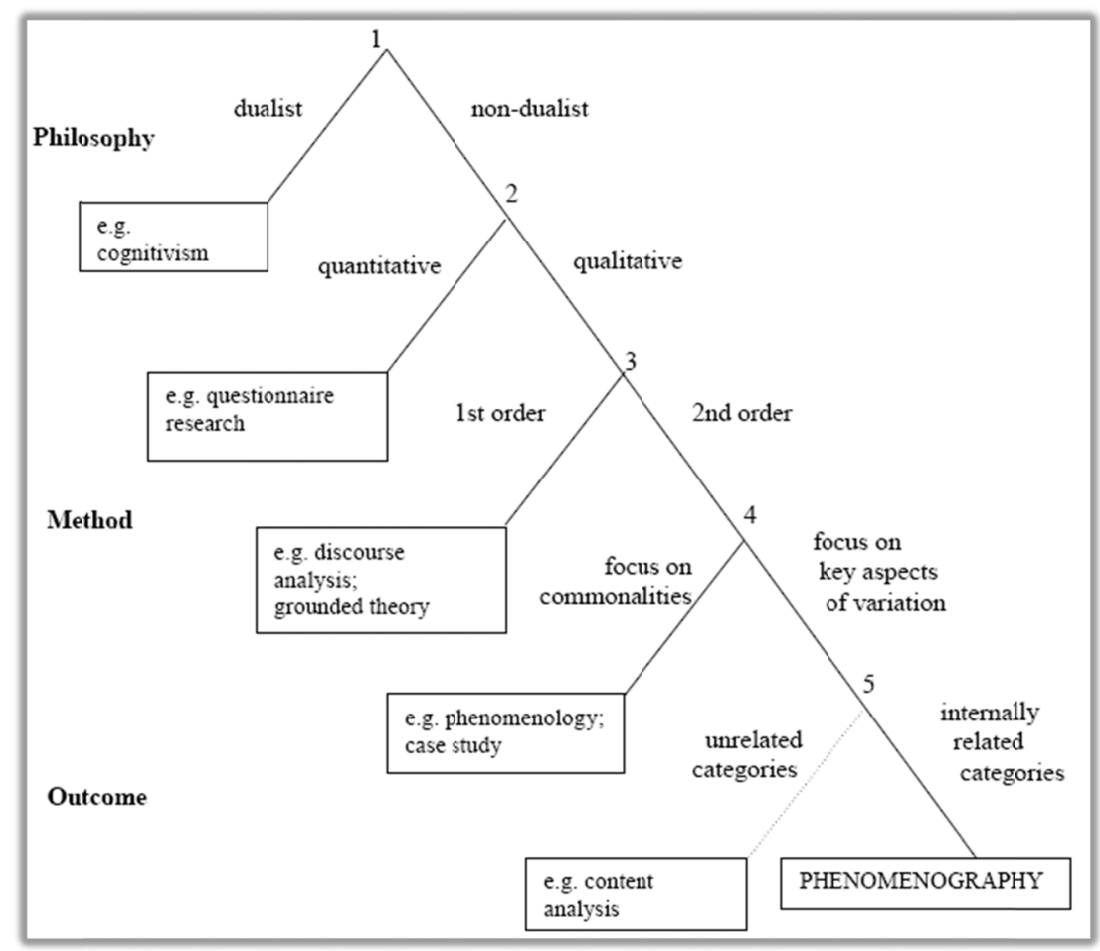

Figure 1. Defining Phenomenography (Source: Trigwell, 2006, p. 369)

There are several reasons for employing a phenomenographic approach. In the first place, the aim of the research - investigating a group of Chinese postgraduate participants' different ways of experiencing the phenomenon of learning in a university - matches well with the definition of phenomenography. The second-order perspective claimed by phenomenography would be beneficial to both data collection and analysis and may further improve the scientific nature of the study. The researcher's own view can be bracketed to a great extent, also the influence of existing theories and findings can be controlled well to reveal the students' experience as faithfully as possible. Finally, this research approach has provided a sound analytical tool to make sense of the experience of learning. The construction of outcome space enables researchers as well as readers to look at experience at a theoretical and logical level. 


\section{Conceptions of Learning}

Conceptions of learning are the ways in which students conceive what learning means to them and the possible outcomes (Ellis et al, 2008). It is a crucial research area for phenomenographic tradition, since most studies on the topic of conceptions of learning have often been researched with phenomenographic approach.

The most cited and classical studies on conceptions of learning are conducted by Säljö (1979) and Marton, Dall'Alba and Beaty (1993). Säljö (1979) identified five categories of conceptions of learning, namely: learning as quantitative increase of knowledge; learning as memorising and reproduction; learning as the acquisition of practical knowledge and application; learning as abstraction of meaning; and learning as interpretive procedure which aims to understand reality. Decades later, Marton et al's (1993) research revealed similar results, namely learning as 'increasing one's knowledge', 'memorising', 'applying', 'understanding' and 'seeing in a different way'. In the meantime, they added the sixth dimension, which is learning as changing as a person. One could find such research studies across the 1980s (Van Rossum \& Schenk, 1984), 1990s (Franz et al, 1996), 2000s (Byrne \& Flood) and 2010s (Virtanen \& Lindblom-Ylänne, 2010). It is found that there might be some similarities shared among all these investigations, which perhaps could verify Marton's (1994) claim that that there is a limited or finite number of qualitatively different ways to experience a certain phenomenon.

However, in the era of higher education internationalisation, one could hardly conduct a phenomenographic study on domestic students pursuing education in a culturally and socially different country. The only one which may be of relevance was carried out by Abhayawansa and Fonseca (2010), who interviewed a group of Sri Lankan undergraduate accounting students and discovered that although they were experiencing the pedagogical tradition of Australia, their ways of conceiving and approaching learning were still influenced by the traditional collectivist culture. The research reminds us of the inappropriateness to generalise some findings in other culturally distinct contexts. The literature on such topics of both interest and value has yet to be enriched.

\section{Data Collection}

Although there are several methods available for gathering data in a phenomenographic research, the semi-structured interview is considered the most dominant technique. On the one hand, the main questions allowed to keep the interview on track so that it would not lose direction. Nonetheless, for a phenomenographic research study, these could only be viewed as a guide, rather than a rigid and inflexible constraint. Interview questions were made as general and open-ended as possible, so that ample data could be collected. On the other hand, the timely and occasional follow-up questions allowed the researcher to increase the depth of the conversations in order to generate more valuable data. Responses to some follow-up questions were perhaps more insightful and useful for the research (Åkerlind, 2005). Five semi-structured in-depth interviews were carried out to investigate the Chinese overseas learners' conceptions of learning. The core questions included: 'What do you mean by learning?', 'How do you go about learning?', and 'How do you know when you have learnt something?' 
Even though it was a small scale empirical study, the diversity of interviewees had been fully emphasised. As Åkerlind, Bowden and Green (2005) claim: In phenomenography “... small sample sizes with maximum variation sampling, that is, the selection of a research sample with a wide range of variation across key indicators (such as age, gender, experience, discipline areas, and so on), is traditional" (p. 79). Five Chinese postgraduates were selected from a British university. Below is a figure illustrating some key information of all the participants.

\begin{tabular}{ccccc}
\hline Student No. & Gender & Subject & Age & Identity \\
\hline Interviewee 1 & Male & Education & 27 & Doctoral student \\
Interviewee 2 & Female & Education & 27 & Doctoral student \\
Interviewee 3 & Male & Education & 25 & Master student \\
Interviewee 4 & Female & Education & 24 & Master student \\
Interviewee 5 & Male & Education & 33 & Master student \\
\hline
\end{tabular}

Figure 2. Participants' information

\section{Data Analysis \& Analytical Framework}

The procedures used to analyse the data collected followed a seven-step analytical method proposed by several researchers (Dahlgren \& Fallsberg, 1991; Khan, 2014; Sjöström \& Dahlgren):

- Familiarisation step: the transcripts will be read several times in order to become familiar with their content. This step will correct any mistakes within the transcript.

- Compilation step: The second step will require a more focused reading in order to deduce similarities and differences from the transcripts.

- Condensation step: This process will select extracts that seem to be relevant and meaningful for this study.

- Preliminary grouping step: the fourth step will focus on locating and classifying similar answers into the preliminary groups.

- Preliminary comparison of categories: this step will involve the revisions of the initial list of categories to bring forth a comparison among the preliminary listed categories.

- Naming the categories: After confirming the categories, the next step will be to name the categories to emphasise their essence based on the groups' internal attributes and distinguish features between them.

- Final outcome space: in the last step, the researcher hopes to discover the final outcome space based on their internal relationships and qualitatively different ways of understanding the particular phenomena. It will then represent the categories in a hierarchy.

(Khan, 2014, pp. 38-39) 
The what/how framework (Marton \& Booth, 1997), is a critical framework to analyse the basic unit in phenomenography - conception (Marton \& Pong, 2005). Harris (2011) deems that it "allows the conception to be analysed separately from the actions and intentions related to it" (p.109).

The framework was first pointed out by the Swedish researcher Pramling (1983), when she was researching children's conceptions of learning. She concluded that subjects' answers could be categorised into two major questions: "Dealing with what the children perceive as learning", and "Dealing with the children's ideas of how particular learning comes about" ( $p$. 88). The first question could be called the what aspect of learning and the second might be named the how aspect of learning. The results have shown that participants conceive learning as: to do, to know, and to understand, and it could be implemented by doing, perceiving and thinking. As for the relations between the what and how aspects, Pramling (1983) explains that:

Theoretically, all these combinations are possible (i.e., any of the "what" categories can be combined with any of the "how" categories). ... But there is some trend towards a certain correlation, i.e., learning TO DO takes place primarily by DOING; learning TO KNOW takes place primarily by PERCEIVING. Logically, learning to UNDERSTAND comes about in the first hand by THINKING (p.107).

In spite of some special features of these children as subjects, Marton, Dall'Alba and Beaty (1993), consider that the distinction made between what is learned, and how it is learned, is somewhat generalizable. The framework should be advocated and employed in more phenomenographic studies.

In light of the concept of intentionality, Marton and Booth (1997) further explore that the what aspect has a direct object while the how aspect has an indirect object. The direct object means "the content that is being learned", the indirect object refers to "the quality of the act of learning ... what the act of learning aims at" and the act is "the way in which the act of learning is carried out" (p.84). Their analysis can be illustrated by the figure below:

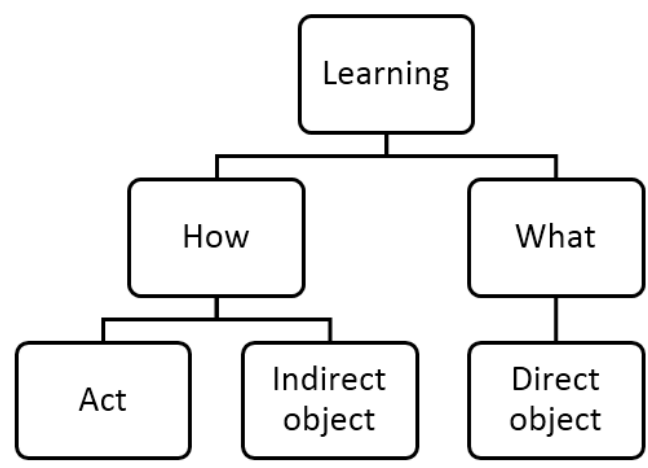

Figure 3. The 'what' and 'how' framework (Source: Marton \& Booth, 1997, p.85) 
Even though this early effort has been made to define the first level (what and how) and the second level (direct object, act, indirect object) of this analytical framework, there are still some different understandings and explanations as Irvin (2006) notices. Therefore it is highly necessary to specify and tailor the definition of these key terms to this study.

In this research, the what aspect of experiencing learning is represented by the 'direct object', meaning the content to be learned. The how aspect of experiencing learning is represented by the 'act of learning' and the 'indirect object of learning'. The 'act of learning' refers to the ways, actions and strategies participants adopted in learning. The 'indirect object of learning' refers to the "intention underpinning the act" (Ellis et al, 2006, p.245), or the "aim of the act" (Marton \& Booth, 1997).

\section{Findings}

\subsection{Conception A. Learning as Knowledge Accumulation}

The conception that learning is the acquisition of knowledge has been expressed by all the five participants. In spite of its dominance, it cannot be taken as an in-depth and sophisticated way to experience learning. As Marton, Dall'Alba and Beaty (1993) state:

It [the increase of knowledge] is a general conceptualisation of learning that covers all the different conceptions. This is because one of the key words in the subject's answer is 'learning', which is exactly what the question is about, and the other keyword, 'knowledge', is not further explored. Thus the subject's answer does not differentiate between different conceptions. We want to suggest that this is the conception from which all the other conceptions develop. In this way it is both prior and superordinate to the other conceptions. Such a general characterisation of learning, without any distinctive characteristics, is thus included by Säljö in the first category of description and we follow his practice here. (p.284)

Similarly, Boulton-Lewis et al (2008) also state that

This category is distinguished by its vagueness and its "taken-for-granted nature" about learning. It is general, inclusive, undifferentiated conceptualisation and included vague non-elaborated aspects of all the other conceptions. Learning increases knowledge (and, in this case, skills) as the label implies and this is often described in quantitative terms. (p.123)

For those participants who were holding this view, their direct object was to obtain knowledge as much as possible. They did not explain personal understanding of learning, or rather they took it for granted. The act of learning could be depicted as receiving. They adopted many sorts of strategies to achieve it, including taking courses, reading, on-site visit, etc. In their views, one could learn something new from the areas one had already been familiar with. Also one might learn brand new things from an untouched area. The indirect object here was also to acquire fresh things and in the meantime their capability of new knowledge acquisition might be improved. 
The first is to accumulate knowledge, you can feel it obviously. For example, I was unfamiliar with this area, but I'll know about something such as scholars and theories when I read some papers. This is a process of pure knowledge accumulation. (Interviewee 1)

I think it is the stimulation of new knowledge. If you didn't know the thing in the past and you hear about it for the first time, this is something you have learnt. (Interviewee 2)

(I want to see) how they implement the idea. How are the British enterprises and other similar agencies operated? (Interviewee 3)

You can learn something you've already learnt, but it should be deeper, or you can learn something new and you've never come across ... (Interviewee 4)

New knowledge and skills that may help to improve you. Something to be infused like cramming schools and taking courses. (Interviewee 5)

In order to acquire what they named as 'new knowledge', it was necessary that the university should be able to deliver something new. More specifically, some subjects had pointed out that the curricula, the modules and the design of learning materials ought to facilitate the intake of fresh untouched knowledge. Additionally the lecturer's role was vitally important here, since he/she might introduce recent research development and frontier theories that they had grasped so that students would be able to expand and update their specialised knowledge base.

(You can learn) many brand new things. ... The set of curriculum is new, and the core modules are new. You may try to find some things interest you and study further. (Interviewee 4)

In the class they (lecturers) don't hesitate to talk about their new research findings. So the students may feel the frontier of theory and it has been developed like this. (Interviewee 3)

\subsection{Conception B. Learning as Applying}

Learning in this category was conceptualised as applying knowledge and procedures, which was also the direct object of this conception. It can be distinguished from the above conception "by the emphasis on explicit application of the knowledge" (Boulton-Lewis et al, 2008, p.124). The act here was to apply or to put knowledge into practice. As a result of it, the indirect object might be the ability of applying the knowledge when the need arises.

... you should put this into practice and see how it functions. You can pick up several theories and apply them. ... (Interviewee 4)

Participants deemed that application might act as a testing tool, i.e., through the process of applying, one could identify which was correct/incorrect and see if he/she had grasped something. Additionally, it was also treated as a key step to bridging theory and practice, yet it needed to be explicitly explained in the class. 
It's to put something into practice. Once you apply it, you can find the correct and incorrect parts. ... so I think the bridge between theory and practice lies in the section of application in the class ... and it ought to be scientifically designed. (Interviewee 1)

When I use it very fluently, I don't have to read again and I totally understand it. (Interviewee 4)

Knowledge learned could be applied to academic situation as well, like writing papers. Interviewee 4 gave an example to illustrate the role of application in academic learning. Obviously it acted as a tool used by teachers to examine the extent to which students had understood the things learnt.

If you understand it, you are able to apply it to writing a paper. Our teacher once explained to us why he read our papers, because he wanted to see how we understood certain things ... whether we've truly understood or conceived it in a totally wrong way.

(Interviewee 4)

As far as the participants were concerned, they all opined that they had to first understand something before applying. In other words, knowledge application should be based on comprehending "how something worked in practice" (Boulton-Lewis et al, 2008, p.124). Thus they hoped that lecturers could clarify the steps, procedures and the scope of application.

\subsection{Conception C. Learning as Obtaining New Perspectives}

In this conception, "it is the change that is emphasised: the learner is changing his or her way of thinking about something, changing the conception of something" (Marton et al, 1993, p.290). The subjects' direct object of learning here refers to gaining some distinct perspectives to see something differently.

... you understand something from one perspective in the past, and then you can comment on the same thing from another perspective, this is a progress. When you can perfect your thinking from different perspectives, it proves that you receive some new knowledge. (Interviewee 3)

(you have) more perspectives to view things...in the past you followed others, but now you're more critical. (Interviewee 5)

The act included thinking about alternative perspectives and reflecting on subjects' own viewpoints. Initially there was a phenomenon that one came across something unexpected, and he/she took it seriously because it made some sense to them. As a consequence, they might question the taken-for-granted views and begin to consider another way of seeing it. This was a typical process of enlightening and changing views. The aim for this act was to understand and evaluate certain alternative perspectives.

It is something unexpected. It enlightens you and then you begin to reflect on it... he provides another perspective and you learn a new viewpoint. ... He introduces more and enable you to reflect on the taken-for-granted. (Interviewee 2) 
All of a sudden it inspires you. ... it inspires your prior experience and future thinking. It enlightens you and challenges your thoughts. You know what to do next. (Interviewee 5)

Group discussion in the classroom was often highly evaluated as a teaching method by most participants, since it facilitated perspective changing. As some said, the members in each group were from distinct backgrounds with varied cultural, social and historical tradition. They might view something common very differently and each argument seemed to be reasonable to some extent. The collision of perspectives and viewpoints made everyone in the group think further.

The group discussion is very important... The teacher poses some questions for us to discuss, and students point out their own opinions from distinct perspectives ... I gained a lot from this process. ... It's a process of active engagement, you're thinking about it... (Interviewee 1)

In every module, students come from different nations, with distinct culture and understandings. These students have different understanding towards a common definition ... it brings more perspectives. (Interviewee 3)

Teachers' attitudes might be another factor. This was important for those students having their own opinion. Positive attitudes such as encouragement and appreciation could promote independent thinking.

... you will find it could be understood in this way, from a different perspective. Some teachers encourage you to think for yourself ... I prefer the former (think for yourself). Because everyone has a distinct way of thinking, ... we now have our own opinions. (Interviewee 4)

\subsection{Conception D. Learning as a Communicational Process}

The above conceptions have been set within some very formal and even narrow classroom learning circumstance. Nonetheless the scope or situation for this final conception has been greatly expanded. Participants' understanding of learning can be embodied in each activity and situation of educational value to them. Some students, in particular some doctoral students had claimed that course taking only took up a tiny part of their learning. The direct object of learning in this conception covers a wide range of things of educational value, which may involve both knowledge and experience. Likewise, students' strategies of learning are various, such as observing, feeling, receiving and reflecting. The indirect object was to comprehend things of educational value.

In the first place, interpersonal communication was regarded as a crucial means to learn something. This was obvious for the two PhD students. One of them deemed it to be the 'academic interpersonal relationship', which meant human relation based on knowledge exchange. They both cherished the formal and informal communications with their supervisors and fellow students, as they felt that new thoughts and ideas might be generated that way. 
... and how to deal with academic interpersonal relationship... (Interviewee 1)

It is more about interaction with the supervisor. New things emerge when we discuss. ... The informal communication with fellow students and teachers. ... Chatting can generate new thoughts. (Interviewee 2)

While the two $\mathrm{PhD}$ candidates stressed the academic development, the masters' students emphasised on the informal aspect of learning. Being in a totally different country, as they stated, one needed to maximise and take full advantage of informal learning, which could include communicating with fellow students who were also from other places, questioning existing thinking and discovering the differences. As a result, one could expand his/her horizon. More specifically, it involved accumulated knowledge, enriched life experience, affluent interpersonal relationship, in-depth insights towards something and an open mind.

When you're in a different country, the most important is informal learning. It is a form of learning irrelevant to your formal and specialised learning, including communication with others, your personal thinking and your impression of the differences you came across... (Interviewee 3)

You come here and expand you horizon, contact with different people, all of these are beneficial to your informal learning. ... More or less I'll communicate with some close students, this is another way of learning. Interaction between us. ... Another one is to contact with other things and people, working together with them. You'll get some feedback from it and thus enhance and improve yourself. ... My understanding to enhance oneself means to enrich your spiritual world, expand your knowledge and horizon, look into things more deeply and be more mature. ... All the students are adults, each has his/her own experience. ... the interaction between students and teachers is interaction between adults. Communication is mutual learning... (Interviewee 5)

\section{Discussion \& Conclusion}

The ultimate product of a phenomenographic study is named as the 'outcome space' (Marton, 1994), which is "the complex of categories of description comprising distinct groupings of aspects of the phenomenon and the relationships between them" (Marton \& Booth, 1997, p. 125). The categories concluded in this research, learning as knowledge accumulation, applying, obtaining new perspectives and a communicational process, are required to be hierarchically constructed. Categories at higher levels are "increasingly complex by incorporating a qualitatively different new element while maintaining the essential elements of the previous category" (Martin et al, 2003, p.250).

In reviewing the findings, it is obvious that 'learning as knowledge accumulation' can be set as the initial conception. In spite of its unexplored and vague characteristics, it is the beginning for the following conceptions, as Marton et al (1993) contend that "this is the conception from which all the other conceptions develop" (p.284). By contrast, Conception B has a very clear definition for learning - applying. It goes further based on the previous conception and has a function of bridging theory and practice. Nonetheless it could not compare, contrast and generate new perspectives to see things differently, which is the 
speciality of Conception C. All of these qualitatively different ways to experience learning have been explicated within the formal educational settings. But subjects with the final conception go beyond it and expand their understanding of learning to a much larger circumstance. They talked about learning in a very broader sense, conceptualising it as a communicational process with both people and physical situations. Therefore, the sequential four conceptions form a hierarchy, with Conception A at the bottom and Conception D at the top as Figure 4 illustrates.

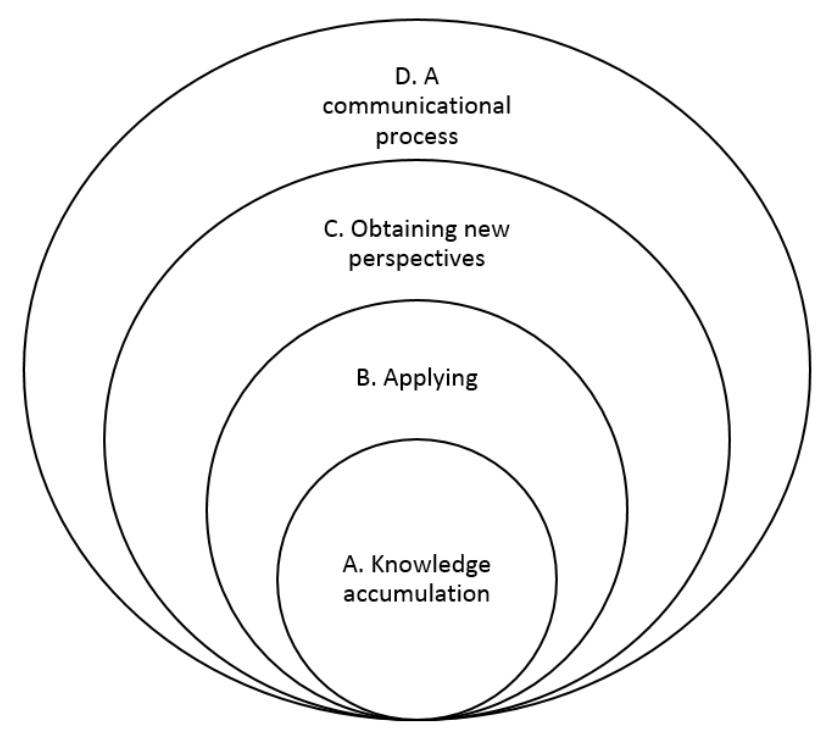

Figure 4. The 'outcome space' for the research

Drawing on Dahlin and Regmi's (1997, p.474) two-dimensional outcome space, the categories can be understood in another way. The depth dimension is composed of the 'signs', meaning the memorisation of words, and the 'signified', referring to "the understanding of phenomena around us". The temporal dimension is composed of the acquiring phase, referring to "when knowledge or information is "take in""; the "phase of knowing or remembering this material" and the "phase of applying what one has learned".

\begin{tabular}{c|cc} 
Depth dimension & Temporal dimension \\
\hline Focus on the 'signs' & A. Knowledge accumulation & Applying \\
& B. Applying \\
Focus on the \\
'signified'
\end{tabular}

Figure 5. The two-dimensional outcome space and the categories 
As Figure 5 shows, Conception $\mathrm{A}$ is located between acquiring and knowing, since it focuses on the intake of new and fresh knowledge. Thus it concerns the literal meaning. Obviously applying ought to be put to the applying phase, but its concentration is on the 'signs', no attempt has been made to seek for the underlying meanings. Both Conceptions C and D can be located in the applying phase in terms of the temporal dimension. Nonetheless Conception $\mathrm{D}$ has a stronger focus on understanding some phenomena in life situations.

This was a small scale study on the Chinese overseas postgraduates' conceptions of learning in a British university. The four conceptions demonstrated that most students understood the phenomenon of learning well and have good experiences of learning.

\section{References}

Abhayawansa, S., \& Fonseca, L. (2010). Conceptions of learning and approaches to learning - a phenomenographic study of a group of overseas accounting students from Sri Lanka. Accounting Education: An International Journal, 19(5), 527-550. http://dx.doi.org/10. $1080 / 09639284.2010 .502651$

Åkerlind, G. (2005). Learning about phenomenography: Interviewing, data analysis and the qualitative research paradigm. In J. Bowden, \& P. Green (Eds.), Doing Developmental Phenomenography, Melbourne: RMIT University Press.

Åkerlind, G., Bowden, J. A., \& Green, P. (2005). Learning to do phenomenography: A reflective discussion. In J. Bowden, \& P. Green (Eds.), Doing Developmental Phenomenography, Melbourne: RMIT University Press.

Boulton-Lewis, G. M., Brownlee, J., Berthelsen, D., \& Dunbar, S. (2008). Child care students' practical conceptions of learning 1. Studies in Continuing Education, 30(2), 119-128. http://dx.doi.org/10.1080/01580370802097710

Byrne, M., \& Flood, B. (2004). Exploring the conceptions of learning of accounting students. Accounting Education, 13, 25-37. http://dx.doi.org/10.1080/0963928042000310779

Dahlgren L. O., \& Fallsberg, M. (1991) Phenomenography as a qualitative approach in social pharmacy research. Journal of Social and Administration Pharmacy, 8, 150-156. http://dx.doi.org/ 10.1007/s10459-010-9255-2

Dahlin, B., \& Regmi, M. P. (1997). Conceptions of learning among Nepalese students. Higher Education, 33(4), 471-493.

Ellis, R. A., Goodyear, P., Calvo, R. A., \& Prosser, M. (2008). Engineering students' conceptions of and approaches to learning through discussions in face-to-face and online contexts. Learning and Instruction, 18, 267-282. http://dx.doi.org/10.1016/j.learninstruc.2007. 06.001

Ellis, R. A., Goodyear, P., Prosser, M., \& O'Hara, A. (2006). How and what university students learn through online and face - to - face discussion: Conceptions, intentions and approaches. Journal of Computer Assisted Learning, 22(4), 244-256. http://dx.doi.org/ 10.1111/j.1365-2729.2006.00173.x 
Forster M (2013) Data-analysis issues in a phenomenographic investigation of information literacy in nursing. Nurse Researcher, 21(2), 30-34.

Franz, J., Ferreira, L., Loh, H., Pendergast, D., Service, M., Stormont, D., Taylor, L., Thambiratnam, D., \& Williamson, B. (1996). Students' and lecturers' conceptions of learning in context: an interdisciplinary study. Teaching in Higher Education, 1(3), 325-339. http://dx.doi.org/10.1080/1356251960010304

Harris, L. R. (2011). Phenomenographic perspectives on the structure of conceptions: The origins, purposes, strengths, and limitations of the what/how and referential/structural frameworks. Educational Research Review, 6(2), 109-124. http://dx.doi.org/10.1016/j.edurev. 2011.01.002

Irvin, L. R. (2006). Teacher Conceptions of Student Engagement in Learning: A Phenomenographic Investigation. Unpublished $\mathrm{PhD}$ Thesis. Central Queensland University.

Khan, S. H. (2014). Phenomenography: a qualitative research methodology in Bangladesh. International Journal on New Trends in Education \& their Implications (IJONTE), 5(2), 34-43.

Martin, E., Trigwell, K., Prosser, M., \& Ramsden, P. (2003) Variation in the experience of leadership of teaching in higher education. Studies in Higher Education, 28, 247-259. http://dx.doi.org/ 10.1080/03075070309297

Marton, F. (1994). Phenomenography. In T. Husen, \& N. Postlethwaite (Eds.), International Encyclopedia of Education (pp. 4424 - 4429). Oxford: Pergamon

Marton, F., \& Booth, S. (1997). Learning and Awareness. Mahwah, NJ: Lawrence Erlbaum Associates.

Marton, F., \& Pong, W. Y. (2005). On the unit of description in phenomenography. Higher Education Research \& Development, 24(4), 335-348. http://dx.doi.org/10.1080/07294360500 284706

Marton, F., Dall'Alba, G., \& Beaty, E. (1993). Conceptions of Learning, International Journal of Educational Research, 19, 277-300.

Paakkari, L., Tynjälä, P., \& Kannas, L. (2011). Critical aspects of student teachers' conceptions of learning. Learning and Instruction, 21(6), 705-714. http://dx.doi.org/10.1016/ j.learninstruc.2011.03.003

Pramling, I. (1983). The Child's Conception of Learning. Goteborg: Acta Universitatis Gothoburgensis.

Säljö, R. (1979). Learning in the learner's perspective: I. Some common-sense assumptions (No. 76). Göteborg: University of Göteborg, Institute of Education.

Sjöström, B., \& Dahlgren, L. O. (2002). Applying phenomenography in nursing research. Journal of Advanced Nursing, 40(3), 339-345. 


\section{Macrothink}

Journal of Education and Training

ISSN 2330-9709

Trigwell, K. (2006) Phenomenography: An approach to research into geography education. Journal of Geography in Higher Education, 30(2), 367ᄀ372. http://dx.doi.org/10.1080/0309 8260600717489

Van Rossum, E., \& Schenk, S. M. (1984). The relationship between learning conception, study strategy and learning outcome. British Journal of Educational Psychology, 54(1), 73-83.

Virtanen, V., \& Lindblom-Ylänne, S. (2010). University students' and teachers' conceptions of teaching and learning in the biosciences. Instructional Science, 38(4), 355-370. http://dx.doi.org/ 10.1007/s11251-008-9088-z

\section{Copyright Disclaimer}

Copyright reserved by the author(s).

This article is an open-access article distributed under the terms and conditions of the Creative Commons Attribution license (http://creativecommons.org/licenses/by/3.0/). 